\title{
OTIMIZAÇÃO DA MOVIMENTAÇÃO INTERNA POR MEIO DO MASP
}

\author{
Vlademi Antônio da Silva (Centro Universitário Farias Brito - FBUni) vlademi10@gmail.com \\ Mauricio Johnny Loos (Centro Universitário Farias Brito - FBUni) mauricioloos@ hotmail.com
}

\section{Resumo}

$\mathrm{Na}$ tentativa de se manter competitiva e deixar seus processos estáveis e robustos, grandes corporações visam aprimorar sua atividade fim, buscando sempre a redução de custos e aumentando sua produtividade, retirando de sua responsabilidade direta as atividades-meio e focar na atividade fim. Vivemos há alguns anos com o mundo globalizado, onde a parceria e o espírito de senso comum para otimizar atividades e reduzir os desperdícios, é uma questão de sobrevivência para as empresas, e na indústria têxtil principalmente, devido seus altos custos em maquinários e capital humano. Neste sentido, o objetivo deste artigo é otimizar a movimentação interna, por meio do MASP (Método de Análise e Solução de Problemas). Buscando ter certeza da viabilidade da terceirização de equipamento para a movimentação de materiais, a ferramenta MASP auxiliou na tomada de decisão, mostrando e evidenciando os impactos e os custos, trazendo uma nova forma de pensar, buscando o alinhamento e o envolvimento da equipe, fazendo com que todos caminhem na mesma direção para alcançar os resultados esperado pela corporação. Devido ao fato dos altos custos do equipamento e indisponibilidade de máquina parada em oficina por defeito, foi traçado um plano de acompanhamento através da metodologia MASP para resolver este problema. Após a implementação dos planos de ação e com o equipamento adquirido, os resultados esperados superaram as expectativas, pois além da disponibilidade de máquina, foi visto que houve uma redução nos custos do setor contribuindo para o resultado financeiro da organização. Com a resolução da questão da terceirização dos equipamentos para movimentação, reduziu-se inclusive a carga de trabalho da oficina, pois a terceirização do equipamento incluía a manutenção do mesmo. Foi mostrado também que a entidade dá importância a sua principal força de trabalho que são seus colaboradores, buscando a melhoria de seus equipamentos, e isso foi uma conquista bastante expressiva.

Palavras-Chaves: Atividade fim, Indústria Têxtil, MASP.

\section{Introdução}

Fundamentalmente as empresas buscam a resolução rápida e eficaz para os seus problemas e com isso a melhoria contínua de seus processos, direcionamento direcionando suas forças para a atividade fim e buscando a satisfação de seus clientes com o foco em alavancar vendas, sem esquecer os outros stakeholders, sociedade, colaboradores, acionistas e governo. O presente artigo buscou na metodologia MASP a fundamentação para solucionar um problema que estava crônico, que era a movimentação com empilhadeira. A movimentação é um desperdício, mas às vezes dependendo da estrutura da empresa é necessária, e deve-se tentar fazê-las da melhor forma. O foco da melhoria contínua não pode ficar somente nos processos diretos (linhas de produção), mas em todos os aspectos da entidade e o processo de adoção do 
MASP não ficará somente nessa linha da movimentação interna, hoje é implantado em toda a cadeia de processo da corporação.

O presente artigo tem o objetivo de otimizar a movimentação interna, por meio do MASP (Método de Análise e Solução de Problemas). O trabalho foi realizado em uma indústria têxtil localizada na zona rural de Pacajus-CE. Diante de do cenário que a área se encontrava, sem sombra de dúvidas algo teria que ser feito, caso contrário o processo iria travar. Até então eram muitas reclamações dos clientes internos e nenhuma solução para eliminar ou minimizar os problemas dos equipamentos. A oficina de movimentação não encontrava uma solução definitiva, ficava apagando incêndio e quando o problema era mais complexo, era necessária a realização dos trabalhos em oficinas externas, sobrecarregando inclusive o equipamento reserva. A compra de peças de reposição era demorada, devido a necessidade de cotação e aprovação das chefias. Dependendo da peça, o fornecedor não tinha a pronta entrega, aumentando o tempo de máquina parada.

Para cumprir seus objetivos, o trabalho está estruturado da seguinte forma: primeiramente será realizada uma revisão de literatura sobre a temática exposta, seguida da metodologia aplicada, onde logo após serão apresentados os resultados obtidos e, por fim, as considerações finais do estudo.

\section{Revisão da literatura}

A seguir é apresentada uma fundamentação teórica referente a Ferramenta MASP, com a intenção de mostrar a visão da literatura, para posteriormente poder-se efetuar as análises para as tomadas de decisões no campo de trabalho com o intuito de melhoria para os processos.

\subsection{MASP}

A Metodologia de Análise e Solução de Problemas, também conhecida como MASP, é um método para solução de problemas teve sua origem na Ásia, especificamente no Japão, chegando ao Brasil na década de 1980 a 1990. Esse método é um caminho complexo com a finalidade de soluções de problemas nas entidades. Essa metodologia procura melhorar e controlar a qualidade de produtos/serviços ou processos. O MASP é ainda um método que visa envolver as equipes de forma estruturada e racional com o objetivo sistêmico de melhoria 
contínua dos processos nas organizações, buscando a solução de problemas e alcançar os resultados com redução dos custos ou aumento da produtividade e do faturamento das organizações.

O MASP segue uma linha de raciocínio ordenada, com passos pré-determinados que visa identificar o problema, buscar as causas que prejudicam a solução, verifica e analisa as hipóteses para encontrar qual é a causa principal do problema, buscar eliminar/reduzir essas causas, bloqueando com plano de ação eficaz. Garantir efetivamente que as causas foram eliminadas é de fundamental importância para garantir o sucesso do processo e resultado eficaz dos processos, alcançando melhores resultados através da qualidade dos produtos/serviços, processos mantendo sempre a melhoria contínua (Kaizen).

Para Campos (2004), a metodologia MASP possui oito etapas para a sua implementação, onde no quadro 1 pode-se identificar essas etapas e a discriminação de cada uma delas no processo para análise na busca de soluções dos problemas em qualquer linha de trabalho, na produção de produtos ou prestação de serviços.

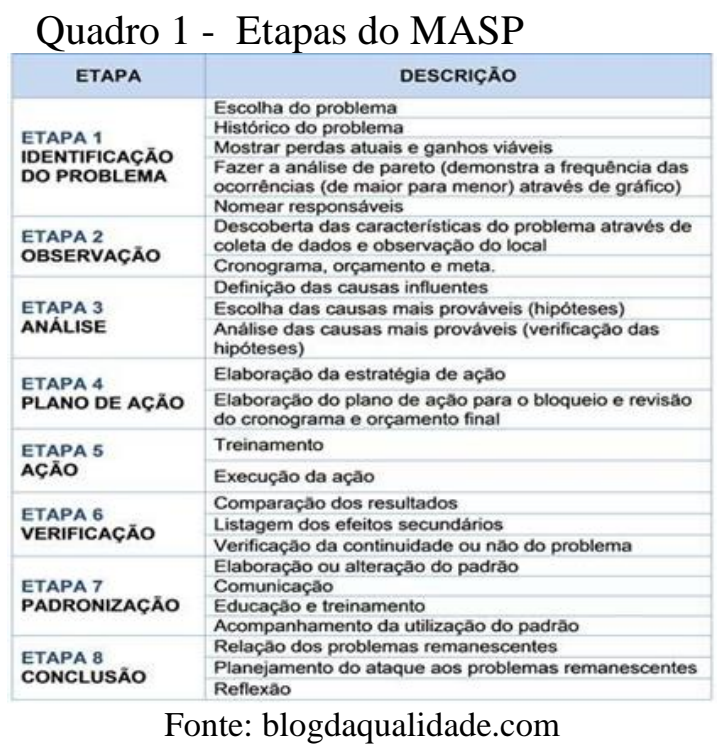

Para Werkema (1995), as sete ferramentas do MASP também chamadas de ferramentas da qualidade podem ser descritas da seguinte forma:

a) Folha de verificação: seu principal objetivo é facilitar da melhor forma possível a coleta de dados e organizar esses dados durante a coleta, eliminando a necessidade de retrabalhos manuais. Esta ferramenta funciona como um formulário com os itens a serem investigados já impressos, de forma a facilitar a coleta de dados; 
b) Diagrama de causa e efeito: conhecido também como Diagrama de Ishikawa, esta ferramenta é usada para pontuar e apresentar as possíveis causas para um determinado problema e assim poder listar as medidas corretivas que deverão ser adotadas;

c) Diagrama de dispersão: é usado quando se tem a necessidade de visualizar o que acontece com uma variável quando uma outra variável sofre algum tipo de alteração. Dessa forma é possível saber se as duas possuem algum tipo de correlação (uma característica da qualidade e um fator que a afeta;

d) Estratificação: consiste na divisão de um grupo em diversos subgrupos com base em fatores apropriados, conhecidos como fatores de estratificação, como: métodos, medidas, equipamentos, insumos, pessoas e condições ambientais;

e) Histograma: seu objetivo é conhecer as características de distribuição associada a alguma população de interesse, neste caso se retira uma amostra desta população e se mede, para os elementos da amostra, os valores assumidos pela variável considerada;

f) Diagrama de Pareto: consiste em um gráfico de barras verticais informando através de números percentuais de forma a evidenciar os maiores índices de causas e assim priorizá-los. O princípio de Pareto estabelece uma relação 80/20, ou seja, para a resolução de $80 \%$ dos problemas deve-se atacar $20 \%$ das causas das perdas que a empresa vem sofrendo com a ocorrência dos problemas indicados;

g) Gráfico de controle: também conhecido como carta de controle, essa ferramenta consiste em identificar a variabilidade do processo e assim poder-se traçar alternativas para a estabilização do mesmo.

\subsection{Kaizen}

A etimologia da palavra Kaizen vem de Kai, que significa modificar, e Zen, que significa para melhor (MARTINS e LAUGENI, 2005). Criada no Japão pelo engenheiro Taichi Ohno, vem com o objetivo de reduzir os desperdícios produzidos nos processos produtivos, visando a melhoria contínua e a qualidade dos produtos, buscando o aumento da produtividade. Essa ferramenta se destacou com sua aplicação no Sistema Toyota de Produção. Womack e Jones (2004) afirmam que o termo Kaizen significa como "melhoria incremental contínua" através 
de atividades normalmente realizadas pelos funcionários da organização, que agem no objetivo de eliminar os desperdícios ou problemas relacionados a produção e identificados nos fluxos produtivos, através da aplicação de técnicas de mapeamento do fluxo de valor.

Para Guarnieri et al. (2008), o ápice da melhoria contínua passa pela adoção de procedimentos que contemplem a avaliação nos processos, na busca da satisfação do cliente, e da qualidade de vida na organização e no ambiente de trabalho.

Segundo Leite (2007) as pessoas possuem habilidades específicas, e esses comportamentos e ações precisam evoluir e tem que ser sustentados ao longo prazo, e precisam da melhoria contínua.

Wittenberg (1994) enumera dez regras fundamentais para aplicação do Kaizen, apresentadas no quadro 2.

Quadro 2 - 10 Regras para o Kaizen 10 Regras para o Kaizen

\begin{tabular}{|c|}
\hline 10 Regras para o Kaizen \\
\hline Descartar as ideias tradicionais e fixas relacionadas à produção. \\
\hline Pensar sobre como fazer, não por que isso não pode ser feito. \\
\hline Não produzir desculpas. Iniciar questionando as práticas atuais. \\
\hline Corrigir os erros de uma vez por todas. \\
\hline Não gastar dinheiro para o Kaizen. \\
\hline Tero botivo pretendido. \\
\hline Perguntar senso, ao se deparar com as adversidades. \\
\hline Encinco vezes e buscar as causas raízes. \\
\hline Saber que as ideias Kaizens são infinitas. \\
\hline Fonte: Adaptado de Wittenberg (1994).
\end{tabular}

\section{Procedimentos metodológicos}

Este trabalho foi baseado em um estudo de caso (Gil, 2002), com o objetivo de mostrar a aplicabilidade de terceirizar a empilhadeira para movimentação de insumos no processo produtivo, sendo que o escopo do trabalho restringiu- se ao setor de depósitos de fios.

A empresa abordada é líder no segmento de Índigo e Brim na América Latina, com suas principais fábricas no Brasil, mas com fábricas também na Argentina e Equador, com distribuição de seus produtos em toda a América e Europa, buscando sempre a inovação de seus produtos e melhoria de seus processos.

Como o foco da empresa é a produção de Índigo e Brim, foi levantado que haviam muitos desgastes e esforços em processos secundários. Por meio da metodologia MASP, verificou-se 
a oportunidade de terceirização das empilhadeiras, e direcionando assim os esforços somente para a atividade fim.

\section{Apresentação e discussão de resultados}

\subsection{Situação anterior}

Foi evidenciado que o equipamento quebrava muito devido ao trajeto, ao tipo de material transportado e ao tempo de vida do equipamento. Se passava muito tempo com o equipamento parado na oficina, devido a decisão gerencial de não ter estoques de peças. Quando qualquer peça quebrava, era feita uma cotação e se solicitava a compra, com isso o setor ficava sem o equipamento para movimentar os materiais, atrasando o processo. A figura 1 mostra um exemplo de uma empilhadeira com problema no motor.

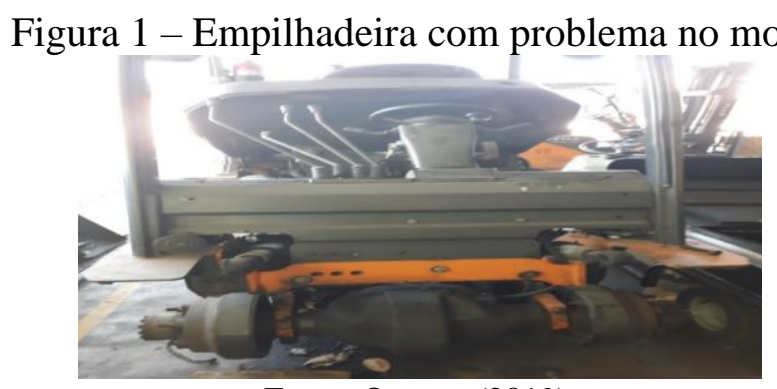

Fonte: $\mathrm{O}$ autor (2019).

A figura 2 mostra um exemplo de uma empilhadeira aguardando peça para ter a manutenção necessária realizada.

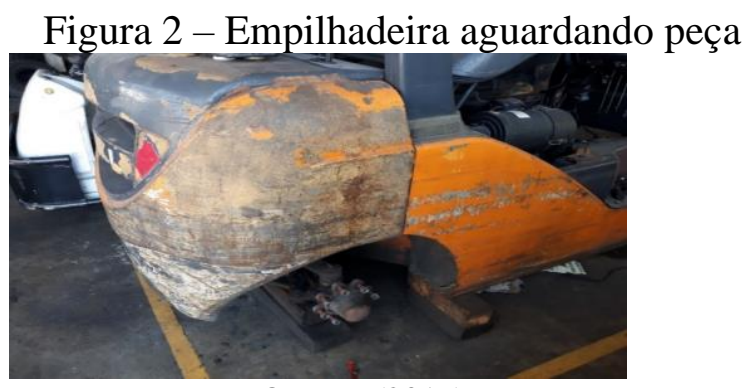

Fonte: O autor (2019).

Na figura 3 podem ser vistas as maiores incidências de defeitos mostrados em Pareto. Como relatado anteriormente, muitos desses equipamentos não tem estoque, gerando um tempo muito alto de máquina parada. 
Figura 3 - Estratificação dos defeitos

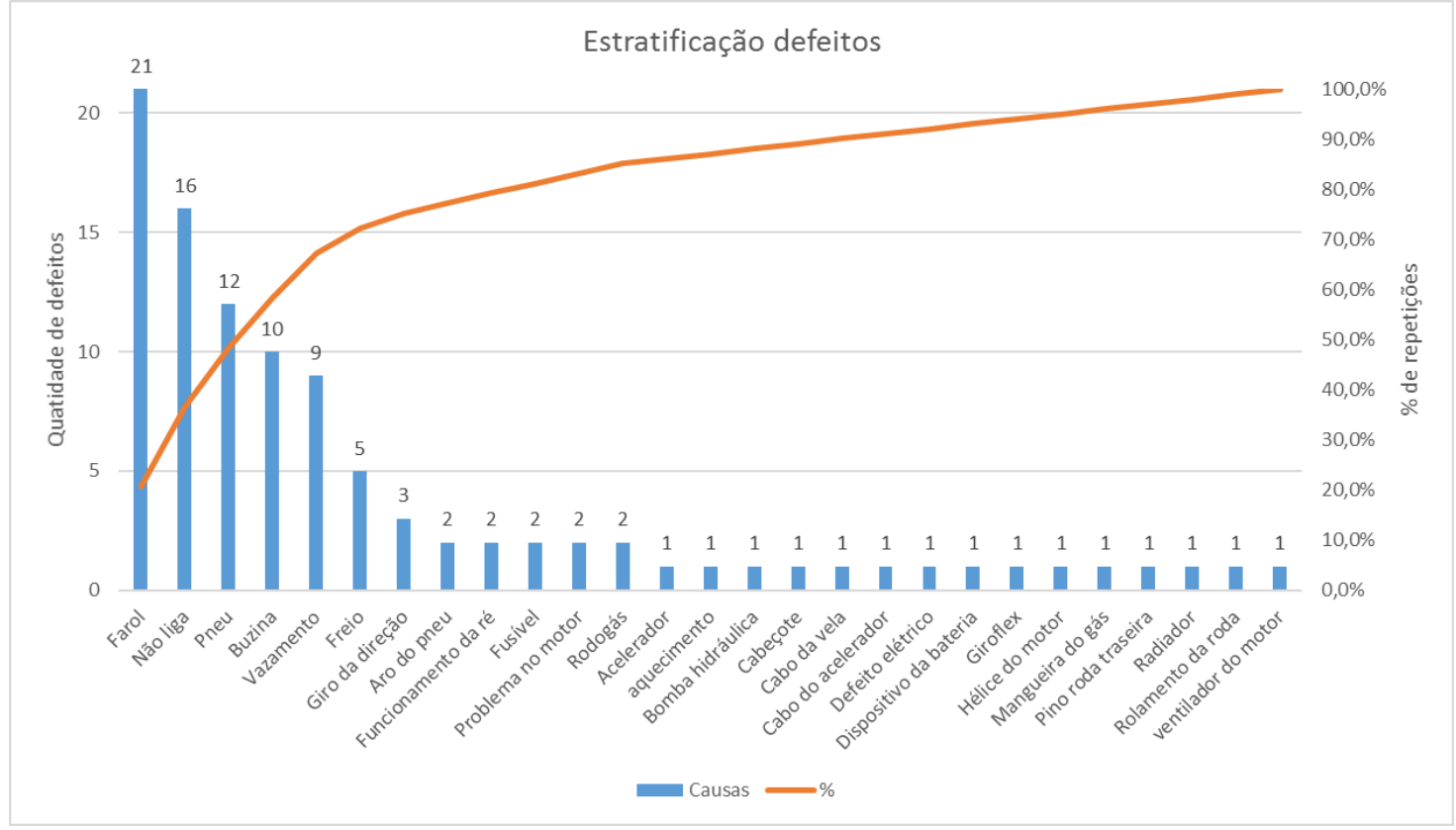

Fonte: O autor (2019).

Nas figuras 4 e 5 podem ser vistos os gastos mensais sendo muito oscilantes.

Figura 4 - Gastos mensais 2016

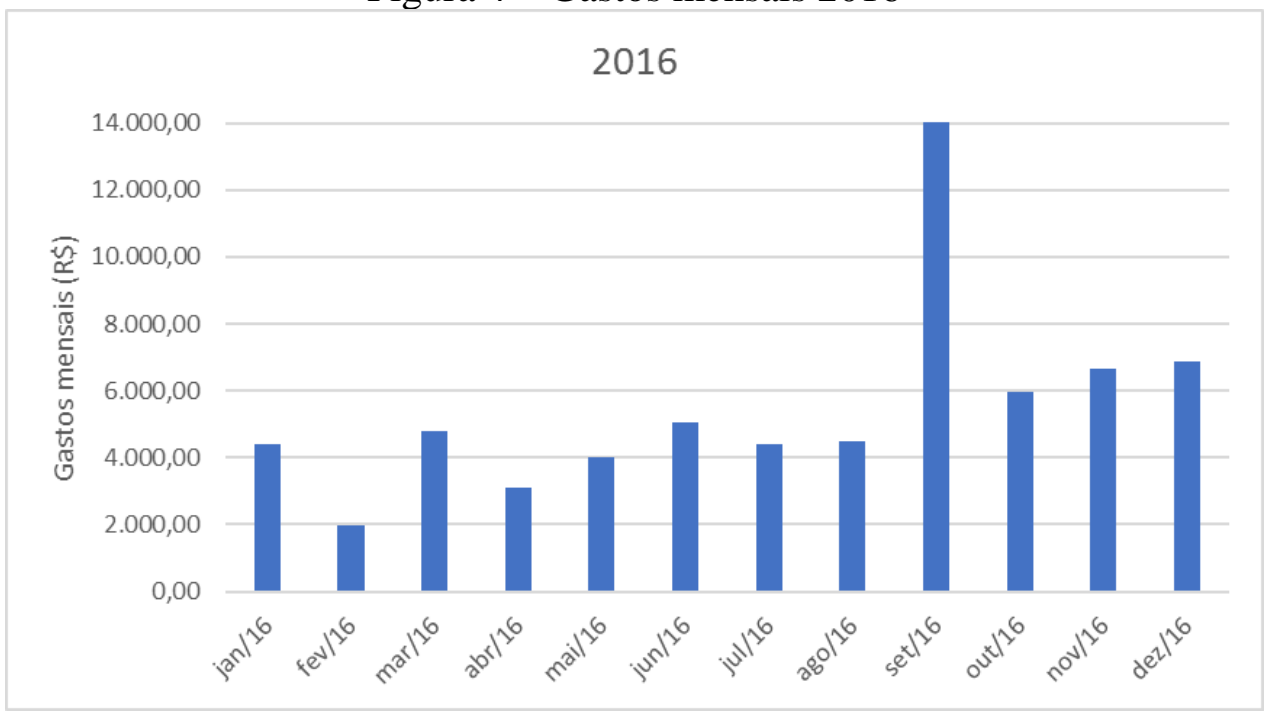

Fonte: O autor (2019). 
Figura 5 - Gastos mensais 2017

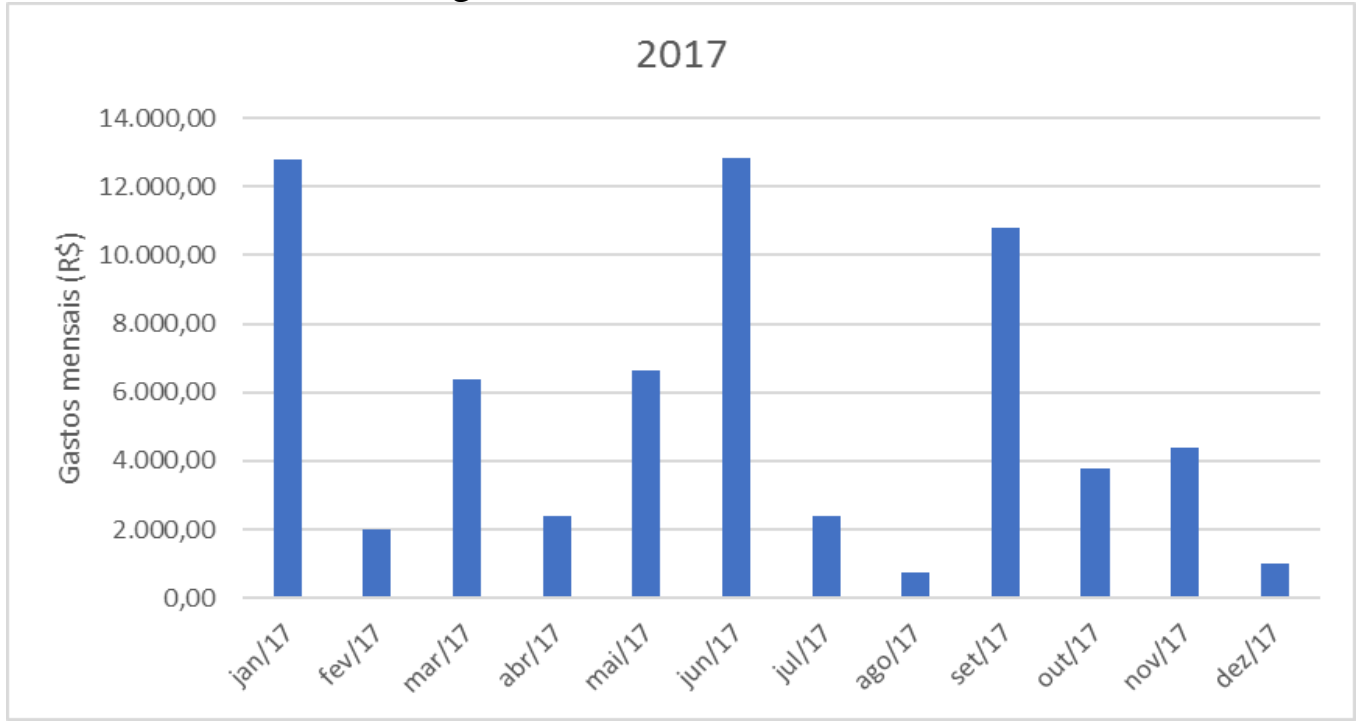

Fonte: O autor (2019).

\subsection{Situação atual com melhorias implementadas}

Após a aprovação do MASP no final de 2017, foi solicitada para a célula de contratos, a terceirização da empilhadeira, que foi efetivada em janeiro de 2018 com um custo fixo mensal de $\mathrm{R} \$ 3.299,00$, conforme mostra a figura 6 .

Figura 6 - Gastos mensais 2018

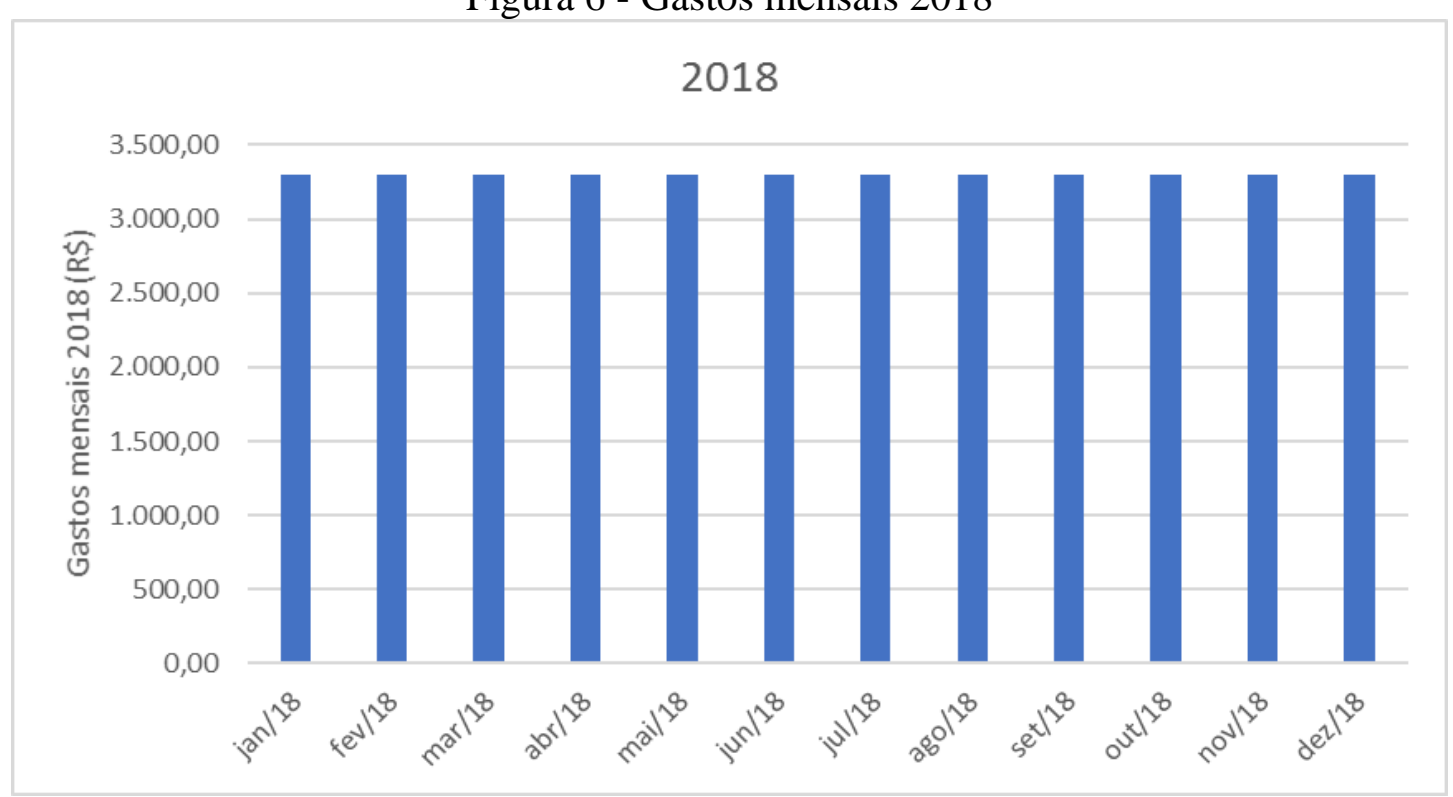

Fonte: O autor (2019).

Com a contratação de uma empresa especializada em locação de equipamentos, a disponibilidade da empilhadeira para o setor ficou integral, a nova empresa garantiu:

a) Equipamentos de no máximo dois anos de uso; 
b) Manutenção preventiva regular;

c) Manutenção corretiva em no máximo $24 \mathrm{~h}$.

$\mathrm{Na}$ figura 7 verifica-se a queda significativa nos custos com empilhadeira, além de uma regularidade nos gastos mensais, situação que não acontecia nos anos de 2016 e 2017 como mostraram as figuras 4 e 5 .

Figura 7 - Comparativo dos custos 2016 a 2018

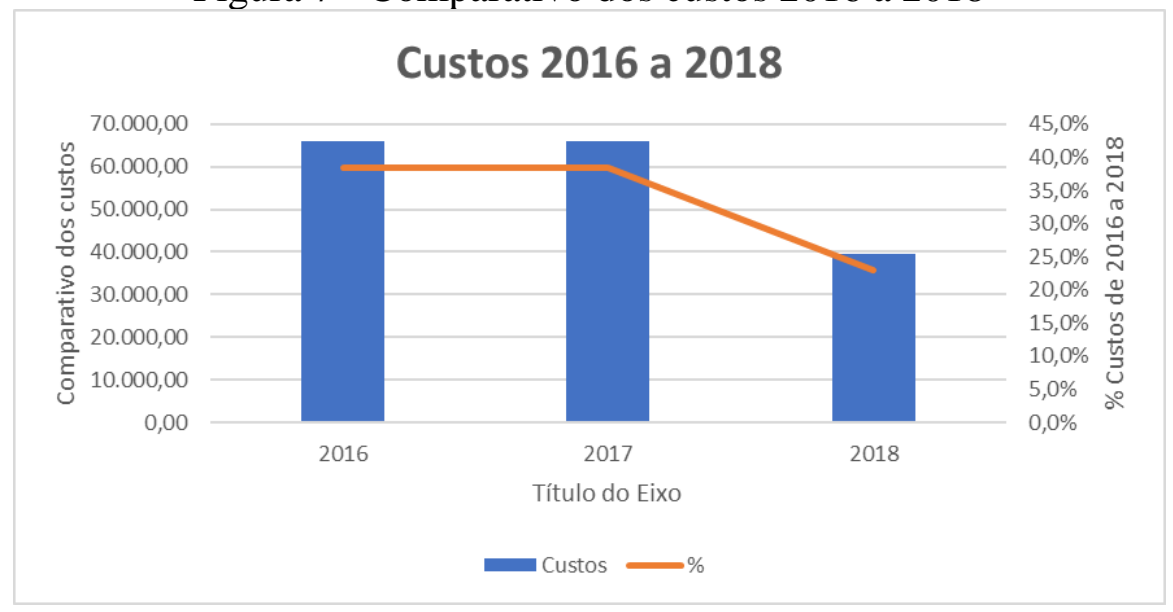

Fonte: O autor (2019).

\section{Conclusões}

Com os números apresentados, a locação da empilhadeira foi a melhor alternativa para a empresa. Terceirizando o equipamento e consequentemente a manutenção desse equipamento, a empresa pode direcionar seus esforços para o foco principal que é sua gestão eficaz para a produção de índigo e brim, buscando a melhoria contínua para ser a maior produtora de índigo e brim do mundo.

Foi identificado também, o bem-estar dos usuários (Operadores de Empilhadeira), visto que os mesmos relataram um maior conforto, devido ser um equipamento novo, com todos os itens de segurança funcionando sem falhas, contribuindo assim para a não ocorrência de acidentes, que é uma meta e um desafio para as empresas, principalmente do ramo industrial.

\section{REFERÊNCIAS}

CAMPOS, V.F. Gerenciamento da rotina do trabalho do dia-a-dia. Nova Lima: INDG Tecnologia e Serviços Ltda., 2004. 266.: Il

GIL, A. C. Como elaborar projetos de pesquisa. 4. ed. São Paulo: Atlas, 2002. 
GUARNIERI, P.; PAGANI, R. N.. Sistema de custo Kaizen. II Encontro de Engenharia e Tecnologia dos Campos Gerais, v. 14, 2008.

LEITE, G. Administração da produção: A evolução com a ferramenta de melhoria contínua no Japão. Revista Técnica IPEP, São Paulo, SP, v. 7, n.1,p. 25-31, jan./jun. 2007.

MARTINS, P.G., LAUGENE, F.P. Administração da Produção. São Paulo: Saraiva, 2005.

WITTENBERG, G. Kaizen-The many ways of getting better. Assembly Automation, v. 14, n. 4, p. 12-17, 1994.

WOMACK, J. P.; JONES, D. T. A mentalidade enxuta nas empresas Lean Thinking: elimine o desperdício e crie riqueza. Elsevier Editora, 2004.

WERKEMA, M.C.C. As Ferramentas da Qualidade no Gerenciamento de Processos. Vol. 1. Belo Horizonte, MG: Fundação Christiano Ottoni, Escola de Engenharia da UFMG, 1995. 